\title{
APPLICATION OF NUMERICAL METHODS, DERIVATIVES THEORY AND MONTE CARLO SIMULATION IN EVALUATING BM\&FBOVESPA'S POP (Protected and Participative Investment)
}

\author{
Giuliano Carrozza Uzêda Iorio de Souza ${ }^{1}$, Carlos Patrício Samanez ${ }^{2 *}$, \\ Gustavo Santos Raposo ${ }^{3}$ and Antonio Carlos Gonçalves ${ }^{4}$
}

Received March 5, 2009 / Accepted August 24, 2010

\begin{abstract}
This article presents a practical case in which two of the most efficient numerical procedures developed for derivative analysis are applied to evaluate the POP (Investment Protection with Participation), a structured operation created by São Paulo Stock Exchange - BM\&FBOVESPA. The first procedure solves the differential equation through the use of implicit finite differences method. Due to its characteristics, the approach makes it possible to run sensitivity analysis as well as price estimation. In the second, the problem is solved by Monte Carlo simulation, which facilitates the identification of the probability related to the exercise of the embedded options.
\end{abstract}

Keywords: numerical methods, simulation, derivatives.

\section{INTRODUCTION}

The international integration of financial markets has stimulated the development of new instruments to enable participants to adopt more sophisticated hedge and investment strategies. It is possible to observe, in the wake of innovations in the derivatives market, a raise in the complexity of the products traded that, in conjunction with the interest in evaluating them, has led the knowledge related to this area to experiment significant development. Some examples of such products are the Liquid Yield Option Note (LYON) created by the Merrill Lynch, the option on one-day interbank deposit futures and the option on daily adjustment, launched by the

\footnotetext{
*Corresponding author

${ }^{1}$ Vale International, Global Risk Management Department, Chemin du Glapin, 4, 1162 St. Prex, Switzerland.

E-mail: giuliano.carrozza@vale.com

2 Department of Industrial Engineering PUC-Rio, Rua Marquês de São Vicente, 225, Gávea, 22453-900 Rio de Janeiro, RJ, Brazil. E-mail: cps@puc-rio.br

${ }^{3}$ Vale International, Global Risk Management Department, Chemin du Glapin, 4, 1162 St. Prex, Switzerland. E-mail: gustavo.raposo@vale.com

${ }^{4}$ Department of Mathematics, UFRRJ, Rodovia BR 465 Km 7, 23890-000 Rio de Janeiro, RJ, Brazil.

E-mail: antoniogon@ufrrj.br
} 
BM\&FBOVESPA, among others. Even if the application of the basic concepts developed by the first authors who studied the derivatives market, such as those presented in the works by Black \& Scholes (1973), Merton (1973), Black (1974), Cox et al. (1979), among others, are kept present in the most recent pricing models, renewed efforts are required in the extension of some of these works and in the improvement of the proper numerical methods for the solution of several issues related to the topic, such as the Finite Difference method and the Monte Carlo simulation method, applied to this work.

Black \& Scholes (1973) established the bases of the modern financial options theory, when they developed an equilibrium model that did not need any restrictive assumption on the individual preferences regarding risk, or on market price formation in equilibrium. They achieved that through the establishment of a "risk-free" portfolio, whose pricing arises out of non-arbitration conditions. The model defines a differential equation that describes price behavior for the derivative that, in conjunction with proper boundary conditions, is used under certain circumstances to derive an expression that allows the determination of the value of an European-type call option.

One of the characteristics of the Black \& Scholes model - also present in Merton (1973), Black (1974) and Cox et al. (1979) models -, is the evaluation based on the so-called risk-neutral world. In the risk-neutral evaluation, it is not assumed that the investors' preferences before risk are neutral, and it does not use actual probabilities, but the risk-neutral probabilities or also called martingale measures.

According to the Black \& Scholes line, Merton (1973a) extended the model so that it envisaged the possibility that the underlying actions might distribute dividends, what would eventually also enable applications in the evaluation of future options, stock indexes and currencies. Additionally, in another important article, Merton (1972b) showed the main relationships between call and put options.

Black (1976) developed an future options pricing model for commodities, based on the assumption that the future price follows the same stochastic process of stock prices used by Black $\&$ Scholes, the Geometric Brownian motion (GBM, defined below). Although it has originally been developed to evaluate options on futures, the same model also generated applications in the evaluation of options on interest rates, such as those developed in works by Vasicek (1977) and Black et al. (1990).

As regards the evaluation of American options, some authors tried to develop analytical approaches, such as Johnson (1983), MacMillan (1986), Barone-Adesi \& Whaley (1987), among others. Given the difficulty to find analytical solutions in certain situations, the numerical methods have become a fundamental tool to solve problems with complex derivatives. Cox et al. (1979) developed the so-called Binomial model, a very useful and popular technique to price an option, applicable both to European and American options. In this model, the different trajectories that may be followed by the underlying asset during the period of maturity for the option are listed. By using a risk-neutral evaluation and a risk-free interest rate as discount rate, the option value at each tree node is obtained, on a recursive basis, until the option value at the start date is obtained. 
Brennan \& Schwartz (1978) developed applications for the Finite Difference method in the evaluation of options. That method consists of the discretization of the differential equation satisfied by the derivative, which is converted into a set of interactively resolved difference equations. Authors such as Samanez et al. (2002) applied that method to evaluate convertible securities with American call options and European put options implicit in the contract.

As the Monte Carlo simulation (MCS) works on uncertain situations in order to determine expected values for unknown variables, it may be defined as a method for statistical tests in which the values are established through random selection, where the likeliness of choosing a certain result among all the possibilities is obtained by means of a random sampling to identify events. In the SMC, the factors which are not known with certainty are called random variables, whose behavior is described by a distribution of probabilities.

The SMC technique deserves to be stood out as a numerical method to evaluate derivatives, and its first application to the evaluation of European options was carried out by Boyle (1977). Some recently developed models bring down the belief that the simulation methods would be applicable only to the evaluation of European options, that is, it was thought that they had no flexibility for the evaluation of American options. Two outstanding models in this sense were the models by Grant, Vora \& Weeks (1996) and the Least-Squares Monte Carlo model, by Longstaff $\&$ Schartz (2001). Therefore, in finance theory, the Monte Carlo simulation has been largely used in the calculation of option, in market and credit risk assessment, in the calculation of Value at Risk (VaR) in the analysis of investment projects, in the solution of Real Options, among others. Iorio et al. (2006) and Samanez et al. (2002) presented an application of these models in the evaluation of complex convertible securities. Araújo (2004) applied Least-Squares Monte Carlo method to evaluate the Real Options imbedded in investment projects.

As an Implicit Finite Difference method and the Monte Carlo simulation method to evaluate the POP, this article is divided into five sections. The section 2 focus on detailing general aspects concerning POP, describing its operation, characteristics and details. The section 3 present the methodologies and steps to be followed in the definition of the pricing models used in POP pricing. In section 4, the two POP pricing models are applied, the results obtained are compared with those observed in the market on the dates analyzed, as well as POP values resulting from the application of Black \& Scholes (1973) model in the pricing of options embedded in the security. In this section, the sensitivity of the security vis-a-vis changes in specific parameters is evaluated, as well as the behavior of the likeliness to exercise the options embedded before changes in the investor's return expectation regarding the isolated investment in the underlying action. Finally, section 5 is dedicated to final comments and conclusions.

\section{DETAILING OF POP}

The POP (Protected and Participative Investment), which has been under negotiation since 09.02.2007, is a variable income product, negotiated at BM\&FBOVESPA, which provides a protection against possible losses (depreciation) of the stock investment in exchange for a par- 
ticipation in the potential gains in this investment. This is obtained through the combination of application in stock and application in its derivatives.

It works as follows: when the investor chooses which level of POP he/she will invest in, he/she defines the level of protection desired. If the stock drops, he/she receives the amount of capital protected, thus covering the risk corresponding to the depreciation. In turn, if the stock rises, the investor gives up a part of the profit obtained with the appreciation of the stock.

The amount of protected capital chosen may be lower than the amount invested (price paid by the POP). Rather than stock, it is a combination of three instruments. POP is comprised by a certain stock in the spot market and its respective call and put options in the options market. All of the above is combined in adequate quantities and proportions to enable the construction of protection strategies for the participative investment. Although the POP is comprised by three instruments, one single order or instruction is sufficient to buy or sell it in the market.

Depending on the series offered in the market, the purchaser of this product signs up the position of holder in a given underlying stock - and the minimum quantity acquired corresponds to its standard lot - and in European put options on that stock. Additionally, the ladder assumes short position in European call options credited on a certain percentage of the same stock, and the percentage referred may vary from a POP to the next, according to participation percentage defined by BM\&FBOVESPA. Currently, the series authorized for negotiation have participation levels of $70 \%$ or $80 \%$, which is equivalent to assuming positions credited in call options over $30 \%$ or $20 \%$ of the stock acquired in POP, respectively. Besides, it is important to highlight that the strike price and the term of the options are the same, and it also equals to the term of the security itself.

Therefore, the put option offers protection to the investment on its maturity date, thus ensuring a minimum price for the stock acquired. This option is obtained by exercising the right of sale of the underlying stock in case its price in the spot market is inferior to the strike price of the put option. Notwithstanding, setting the security's liquidity aside, one may state that the current value of the strike price for the put options, discounting the risk-free interest rate, represents a minimum threshold for the security price at any instance of time.

As far as the call option is concerned, this represents, in scenarios in which the underlying stock price at maturity date is superior to the strike price of the options, a reduction of participation in the POP holder profit in relation to gains that would be obtained from the isolated purchase of the underlying stock. So, while the protection makes the security more valuable to the investor, the differentiated participation in the profit reduces its value, so that these two influences on the price of the product tend to offset. Therefore, in practical terms, the greatest draw posed by POP is the offer, in a kind of portfolio, the financing of the purchase of put option by selling the call option, so that these securities are generally negotiated at prices very close to that of the underlying stock.

Thus, the POP parameters are the underlying stock, the strike price for the options, the percentage of participation and the maturity date; the latter, as mentioned above, is equal to the series of 
option that compose it. On 25.08.2010, there were POPs authorized by BM\&FBOVESPA and negotiated in the market over four distinct stocks: Petrobras PN, Vale PNA, Bradesco PN and ItauUnibanco PN.

The POP may be defined as follows:

- A position purchased in $Q_{M V}$ stock acquired in the spot market

- A long position in $Q_{O V}$ put options with strike price $X_{O V}$

- A short position in $Q_{O C}$ call options with strike price $X_{O C}$

where: $X_{O V}=X_{O C}$.

When acquiring a certain POP, the protected capital $(P C)$ is defined as:

$$
P C=X_{O V} \times Q_{O V} .
$$

$Q_{O V}$ is the quantity of indexed underlying stock in put options with strike price $X_{O V}$ acquired in POP.

In case the call option is exercised, the participation $(P)$ in the result is defined as:

$$
P=X_{O C} \times Q_{O C}+S_{V V} \times\left(Q_{O V}-Q_{O C}\right) .
$$

where $Q_{O C}$ is the quantity of indexed underlying stock in call options with strike price $X_{O C}$ acquired in POP, and $S_{V V}$ is the price of underlying stock at maturity date.

Equation (2) may also be written as follows:

$$
P=X_{O C} \times(1-P P) \times Q_{M V}+S_{V V} \times P P \times Q_{M V},
$$

where $P P$ is the percentage of participation. By definition of POP, we have $Q_{M V}=Q_{O V}-$ $Q_{O C}$ and $Q_{O V}=Q_{M V}$.

It is worth pointing out that the investor may freely negotiate the assets that comprise the POP, individually or jointly, so that the guarantee of a minimum price for the underlying stock is only valid when the POP is kept until maturity date - or, in special, when the put option is kept until the maturity. When a sale order is given for the security, the execution of the operation is equivalent to assuming inverted positions in relation to those assumed at the moment the security was purchased, that is, the short position is assumed in the underlying stock at the spot market and the holding position in the call option. The taxation is calculated based on the closing of one or more POP components, following the same taxation rules applied on operations with stock and options. Day-trade operations of parts of POP are also admitted, that is, the investor may negotiate POP and, on the same day, totally or partially negotiate the spot position or any of the options, thus dismantling the POP.

The liquidation of POPs' purchases and sales comply with liquidation terms of their parts: In the spot market, the liquidation is on $\mathrm{D}+3$ (third business day after the negotiation) and, in the options market, on D+1 (first business day after the negotiation). In case POP is exercised at maturity date, the liquidation occurs on $\mathrm{D}+3$. 


\section{ASSESSMENT MODELS}

The two models proposed in this work for POP pricing consider that the stochastic variable, the price of the underlying stock, follows a Geometric Brownian motion. The first one refers to the resolution of the differential equation satisfied by the derivative from the Implicit Finite Differences method and, the second one, from the solution through Monte Carlo simulation method. In a possible extension of this work, especially addressing commodities companies stock, one could take into account that the stochastic variable follows a mean-reversion stochastic process, with or without Poisson jump.

\subsection{POP Evaluation by Implicit Finite Differences method}

This first model developed for POP pricing and analysis use the option pricing theory, using the Black \& Scholes (1973) model as main reference. After obtaining the differential equation that determines the security behavior, the numerical procedure known as Implicit Finite Differences method is used.

To estimate the value of an option, the basic assumption to be adopted says that its equilibrium value is the one that impairs gains with arbitration, both from the purchaser and the seller, since the first the former has optimal strategy in relation to put option and the latter has optimal strategy in relation to call option. Therefore, the put options will be exercised whenever the underlying stock price for the option at maturity date is lower than its strike price. On the other hand, the call options will be exercised whenever the underlying stock price for the option at maturity date is higher than its strike price.

Consequence of the strategy to exercise the put option: When building a POP, it is established that, on the maturity date of the embedded security or stock, its value is never lower than the protected capital. Thus, in case the underlying stock value is lower than the strike price for the options, POP value will be obtained as follows:

$$
\text { Valor }_{P O P}=X_{O V} \times Q_{O V}=X_{O V} \times Q_{M V}
$$

Consequence of the strategy to exercise the call option: When building a POP, it is established that, on the maturity date of the embedded security or stock, its value will be in the maximum as much as the value obtained after exercising the call options present in each security added to the sale price for the remaining stock at the applicable spot market price. Therefore, generalizing equation (4) for any value of the underlying stock at maturity date for the security, POP value at that moment may be represented as follows:

$$
\text { Valor }_{P O P}=\min \left[X_{O V} \times Q_{M V}, X_{O C} \times(1-P P) \times Q_{M V}+S_{V V} \times P P \times Q_{M V}\right] .
$$

\subsubsection{Mathematic model}

If the underlying stock price follows the Geometric Brownian motion (GBM), it is assumed that the natural logarithm of the underlying stock price follows a normal distribution, so that the stock 
price and its continuously capitalized price follow a normal distribution. This stochastic process is widely used to describe the behavior of stock prices and several assets-objects, so that this assumption is adopted in the model described herein. Consequently, assuming that the behavior of the underlying stock price follows the GBM:

$$
d S=\mu S d t+\sigma S d Z
$$

where: $S$ represents the value of the underlying stock; $d S$ is the change in the underlying stock value at a time interval $d t ; \mu$ is the expected return rate for the underlying stock; $d t$ is the time interval discretized; $\sigma$ is the standard deviation of the underlying stock return; $d Z=\varepsilon \sqrt{d t}$, but $\varepsilon$ has standardized normal distribution with average zero and standard deviation equal to 1 , and $Z$ follows a GBM also called Wiener process.

The definition of the differential equation satisfied by POP is obtained from the definition of the equilibrium relationship between the prices of the two hypothetical portfolios, in the sense that their prices do not allow the realization of arbitration gains. Considering the stochastic process defined in equation (6) and from the application of Ito's Lemma, the following partial differential equation is obtained (Samanez et al., 2002):

$$
\frac{1}{2} \sigma^{2} S^{2} \frac{\partial^{2} P O P}{\partial S^{2}}+r \frac{\partial P O P}{\partial S} S+\frac{\partial P O P}{\partial t}-r P O P=0
$$

where POP, $S, r$ and $t$ represent, respectively, the value of the security under evaluation, the underlying stock price, the risk-free interest rate and the time. Equation (7) is actually Black \& Scholes' (1973) differential equation, and must be satisfied by derivatives dependant on any asset-object that follows a Geometric Brownian motion. Thus, to price POP, the details regarding the security are taken into account in the boundary conditions for the model. The final security price will be obtained by the resolution of this equation, after defining the proper boundary conditions, which derive from the optimal strategies to exercise call and put options.

\subsubsection{Numerical resolution}

By solving the differential equation (7), subject to the boundary conditions described below, gets an estimate for the security value, given the assumptions adopted so far. As mentioned above, the solution of the problem will be performed from the Implicit Finite Difference method. In the application of the method, the differential equation is converted into a set of difference equations that, as mentioned above, will be resolved interactively.

Therefore, the differential equation that determines POP behavior - equation (7) - assumes the form below (Iorio et al., 2006):

$$
a_{i, j} P O P L_{i, j-1}+b_{i, j} P O P_{i, j}+c_{i, j} P O P_{i, j+1}=P O P
$$

where:

$$
a_{i, j}=-\frac{1}{2} \sigma^{2} j^{2} \Delta t+\frac{1}{2} r j \Delta t ; \quad b_{i, j}=\sigma^{2} j^{2} \Delta t+1+r \Delta t ; \quad c_{i, j}=-\frac{1}{2} \sigma^{2} j^{2} \Delta t-\frac{1}{2} r j \Delta t .
$$


The next step is the discretization of the time instances and the underlying stock price. A quantity of underlying stock prices $(S)$ is chosen spaced equally between 0 and $S_{\max }$, where the price $S_{\max }$ is defined in such a way that it is possible to define POP value at any time instance, in case the underlying stock reaches that value. For discretization of time $(t)$, a quantity of instances equally spaced between the date of evaluation $(t=0)$ and the maturity of the security $(t=T)$ is chosen. For $M+1$ underlying stock prices and $N+1$ time intervals, the graphic representation of the results will be a grid with $(M+1) \times(N+1)$ points, each of which representing a value of the asset for each value of $S$ and $t$. Thus, the possible values for those variables are discretized in a finite number of points, being point $(i, j)$ correspondent to the instant $i \Delta t$ and to the stock price $j \Delta S$. The shorter the steps used in the discretization proposed, the better adjusted will the model be.

\subsubsection{Boundary conditions}

- Boundary condition on maturity date: on the maturity date $(t=T)$ POP value will be obtained from the equation (5):

$$
\begin{gathered}
P O P_{N, j}=\min \left[X_{O V} \times Q_{M V}, X_{O C} \times(1-P P) \times Q_{M V}+j \Delta S \times P P \times Q_{M V}\right] \\
j=0,1,2,3 \ldots M .
\end{gathered}
$$

- Maximum value condition for underlying stock: when the underlying stock value is high enough at any time instance, it will be safe to assume that the call option will be exercised at maturity date. Therefore, from the definition of a sufficiently high value for the stock object $\left(S_{\max }\right.$ ), the security value for the time instances between 0 and $N$ will be:

$$
\begin{gathered}
P O P_{N, j}=\left[X_{O V} \times(1-P P) \times Q_{M V}+M \Delta S \times P P \times Q_{M V}\right] \times e^{-r(N-i) \Delta T}, \\
i=0,1,2,3 \ldots N,
\end{gathered}
$$

where $M \Delta S=S_{\max }$.

- Minimum value condition for underlying stock: if the underlying stock value assumes zero value $(S=0)$, the put option is assumed to be exercised at maturity date, so that the security value for the time instances between 0 and $N$ will be:

$$
P O P_{i, 0}=0, \quad i=0,1,2,3 \ldots N .
$$

Figure 1 illustrates both the discretization process of the parametric space for variables that govern the security price behavior (underlying stock price and time), and the application of the boundary conditions presented in equations (9), (10) and (11).

After defining the boundary conditions, what comes is the recursive use of equation (8) in order to determine the asset value for each of the points that describe the discrete space, comparing the values obtained in each case with the optimal strategy to be adopted. By firstly approaching the points that correspond to instant $T-\Delta t$, that is, with $i=N-1$ :

$$
a_{N-1, j} P O P_{N-1, j-1}+b_{N-1, j} P O P_{N-1, j}+c_{N-1, j} P O P_{N-1, j+1}=P O P_{N, j} .
$$




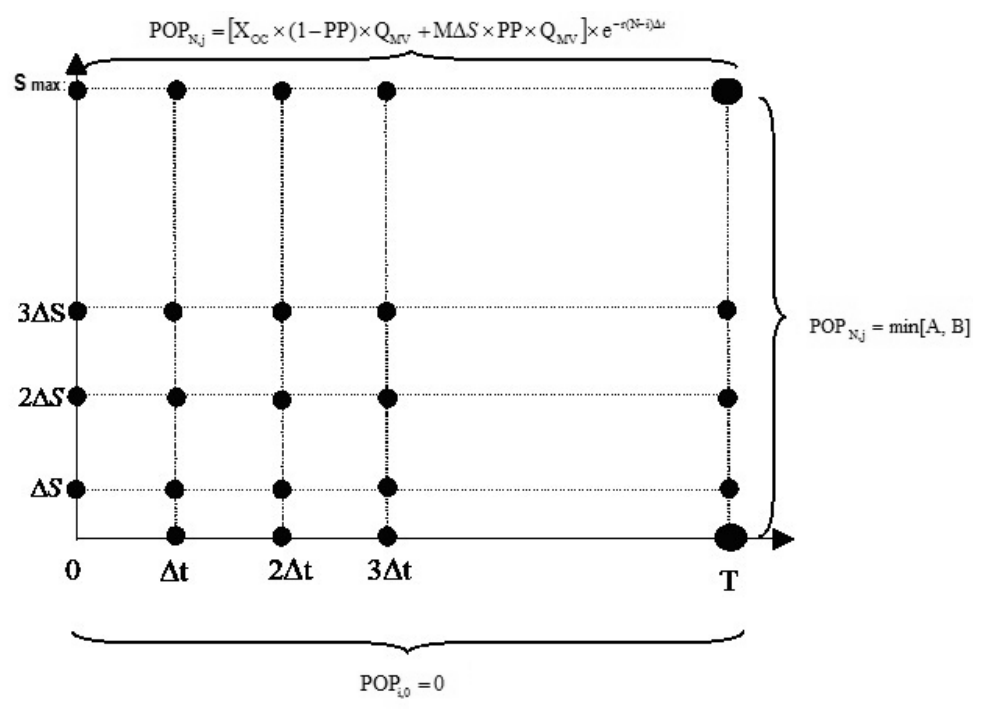

where: $\mathrm{A}=X_{O V} \times Q_{M V} ; \quad \mathrm{B}=X_{O C} \times(1-P P) \times Q_{M V}+j \Delta S \times P P \times Q_{M V}$

Figure 1 - Grid with discretized underlying stock values for each time instance.

Thus, we obtain:

For $j=1: a_{N-1,1} P O P_{N-1,0}+b_{N-1,1} P O P_{N-1,1}+c_{N-1,1} P O P_{N-1,2}=P O P_{N, 1}$

For $j=2: a_{N-1,2} P O P_{N-1,1}+b_{N-1,2} P O P_{N-1,2}+c_{N-1,2} P O P_{N-1,3}=P O P_{N, 2}$

For $j=3: a_{N-1,3} P O P_{N-1,2}+b_{N-1,3} P O P_{N-1,3}+c_{N-1,3} P O P_{N-1,4}=P O P_{N, 3}$

For $j=M-1: a_{N-1, M-1} P O P_{N-1, M-2}+b_{N-1, M-1} P O P_{N-1, M-1}+c_{N-1, M-1} P O P_{N-1, M}=$ $P O P_{N, M-1}$.

\subsection{POP Evaluation by Monte Carlo simulation}

The POP evaluation through the Monte Carlo simulation (MCS) technique may be summarized in three stages:

1. Simulation of underlying stock values at POP maturity date (using the risk-neutral approach);

2. Definition of asset payoff;

3. Pricing of the option through the present average value of payoffs discounted at risk-free interest rate (risk-neutral context).

Thus, similarly to the Finite Difference model described above, in the simulation model will admit that the stock object price will behave according to a Geometric Brownian motion. Therefore, Monte Carlo simulations may be used to simulate price trajectories as described below. 
In case $F(S, t)$ is a function of $S$ and of time $(t)$, where $S$ follows Ito's process (GBM is a particular case of Ito's process), we obtain (Hull, 2005):

$$
d F(S, t)=\frac{\partial F}{\partial S} d S+\frac{\partial F}{\partial t} d t+\frac{1}{2} \frac{\partial^{2} F}{\partial S^{2}} d S^{2} .
$$

For $F(S, t)=\ln S$, and if the process that describes the underlying stock price behavior $S$ is the Geometric Brownian motion, we obtain (Hull, 2005):

$$
d F(S, t)=\left(\mu-\frac{\sigma^{2}}{2}\right) d t+\sigma d Z .
$$

Given the fact that $F$ behavior is described by the stochastic process presented in equation (14), we may define the discrete model of $F$ evolution along time in (15) below. In the limit, when $\Delta t$ tends to zero, we obtain the same continuous process mentioned above:

$$
\Delta F(S, t)=\Delta \ln S=\left(\mu-\frac{\sigma^{2}}{2}\right) \Delta t+\sigma \varepsilon \sqrt{\Delta t} .
$$

By applying the properties of the logarithm to equation (15):

$$
\Delta \ln S=\ln S_{t}-\ln S_{0}=\ln \frac{S_{t}}{S_{0}}=\left(\mu-\frac{\sigma^{2}}{2}\right) \Delta t+\sigma \varepsilon \sqrt{\Delta t} .
$$

Thus:

$$
\frac{S_{t}}{S_{0}}=e^{\left(\mu \frac{\sigma^{2}}{2}\right) \Delta t+\sigma \varepsilon \sqrt{\Delta t}} \text { or } \quad S_{t}=S_{0} e^{\left(\mu \frac{\sigma^{2}}{2}\right) \Delta t+\sigma \varepsilon \sqrt{\Delta t}}
$$

To execute the simulations, the expected return rate for the underlying stock $(\mu)$ must be replaced by the risk-free rate, since it is assumed that underlying asses does not pay dividends, that the fair price of an option does not allow arbitration gains, and the evaluation is made under a riskneutral context (Boyle, 1977). Therefore, from the values of (that follows a normal, standardized distribution), the possible trajectories to be run by the underlying stock value along time are defined.

So, in order to construct a simulation interaction, $N$ independent random samples must be collected from the normal, standardized distribution. When they are replaced in the equation (17), the $S$ values at time instants $0, \Delta t, 2 \Delta t, \ldots, T$, are calculated, providing a possible trajectory for the underlying stock value.

As the number of trajectories increases, a distribution of underlying stock prices at maturity date for the security starts to be built. Consequently, the payoff for each trajectory will be determined by equation (18).

$$
\text { payoff }=\min \left[X_{O V} \times Q_{M V}, X_{O C} \times(1-P P) \times Q_{M V}+S_{s i m} \times P P \times Q_{M V}\right],
$$

where $S_{\text {sim }}$ represents the underlying stock value at maturity date obtained in each simulation.

Finally, POP value will then be obtained by the average of the values present for each payoff, discounted at risk-free interest rate. 


\subsubsection{Calculation of the probabilities to exercise the call and put options}

As the strike price for the call and put options present in the POP is the same, we may state that one of these options will always be in-the-money at maturity date for the security, whereas the other will be out-of-the-money. The only exception is the case when the underlying stock price is exactly the strike price for the options, when they are both at-the-money. Assuming zero probability for this event, we conclude that the sum of probabilities to exercise each one of these options is necessarily $100 \%$.

Thus, this section proposes a methodology to evaluate the probabilities to exercise the implicit call and put options in POP based in Monte Carlo simulations. The probabilities to exercise the put options represent the odds of the protection acquired through POP be adopted. The probability to exercise a call option, in its turn, indicates the odds of the investor incur in a reduction in profit sharing in relation to the gains that would be obtained from the isolated purchase of the underlying stock. The calculation of these probabilities involves the estimation of equiprobable trajectories for the underlying stock price, thus allowing the construction of price distribution for underlying stock at maturity date for the security.

Consequently, the simulations will be carried out by applying the equation (17), being necessary to consider the expectation of return by the investor regarding the investment made directly in stock because, in this stage, the context of risk-neutral evaluation is abandoned. Finally, from the construction of price distribution for underlying stock at maturity date for the security, the exercise of each one of the options for each simulated trajectory will be identified. As each underlying stock value obtained in this procedure has the same likeliness to occur, the probabilities to exercise the options will be estimated through equations (19) and (20).

$$
\begin{aligned}
& \operatorname{Pr} E x_{O V}=\frac{\text { Number of simulations that generated the exercise of put option }}{\text { Total number of simulations }} \\
& \operatorname{Pr} E x_{O C}=1-\operatorname{Pr} E x_{O V},
\end{aligned}
$$

where: $\operatorname{Pr} E x_{O V}$ represents the probability to exercise put option and $\operatorname{Pr} E x_{O C}$ the probability to exercise the call option.

\section{APPLICATION OF THE MODEL}

In order to evaluate the two models developed, we selected fours POPs, whose characteristics are described below. Both were applied for the calculation of the price for these securities between February $9^{\text {th }}$ and February $23^{\text {rd }}, 2007$.

- VALE70 $\rightarrow$ Underlying stock: Vale PNA N1 (VALE5); percentage of participation: 70\%; strike price for the options: $\mathrm{R} \$ 60$; maturity date: 20.08.2007.

- VALE80 $\rightarrow$ Underlying stock: Vale PNA N1 (VALE5); percentage of participation: 80\%; strike price for the options: $\mathrm{R} \$ 55$; maturity date: 20.08.2007. 
- PETR70 $\rightarrow$ Underlying stock: Vale PNA PETR4 (VALE5); percentage of participation: $70 \%$; strike price for the options: R\$ 45; maturity date: 20.08.2007.

- PETR80 $\rightarrow$ Underlying stock: Vale PNA PETR4 (VALE5); percentage of participation: $80 \%$; strike price for the options: R\$ 40; maturity date: 20.08.2007.

In addition to the characteristics of each POP described above, the other input parameters used by each model were:

- Number of business days between February $9^{\text {th }}, 12^{\text {th }}, 13^{\text {th }}, 14^{\text {th }}, 15^{\text {th }}, 16^{\text {th }}, 21^{\text {st }}, 22^{\text {nd }}$ and $23^{\text {rd }}, 2007$ (exclusive) and the maturity day for the POPs, August $20^{\text {th }}, 2007$, is 160,159 , $158,157,156,155,154,153$ and 152 , respectively. The discretization of time made in the two models was 0.25 days.

- The volatility was estimated from the standard deviations (in the period of 0.25 days) of historical logarithm returns for each underlying stock between 8.02.2006 and 8.02.2007. Thus, the estimated values for each one of the referenced stock were: Petrobras PN $($ PETR $4=0.946646 \%$ and Vale PNA N1 (VALE5) $=1.042066 \%$.

- The risk-free interest rate used was $1.0783 \%$ in monthly terms, equivalent to the CDI rate in January 2007 , or $0.008986 \%$ in the period of 0.25 days (continuous capitalization).

Specifically, in relation to the Implicit Finite Differences model, the underlying stock values were discretized in intervals of $\mathrm{R} \$ 0.1$. Since the number of discretizations made was 2,500, the maximum value for each underlying stock in the grid represented in Figure 1 was $R \$ 250$ $(\mathrm{R} \$ 0.1 \times 2,500)$. Considering the discretization of the 160 -day term for the securities, this grid was with $(2,500+1) \times(160 / 0.25+1)$ points, each one representing on underlying stock value in each time instance.

As regards exclusively the Monte Carlo simulation model, the number of simulations made in each estimate for POP value was 50,000, although satisfactory convergence has been reached even with a smaller number of simulations. Considering the application of the model for evaluation of POP PETR70 on 09.12.2006, the Table 1 presents the convergence in the model as the number of simulations is elevated.

While, in the Monte Carlo simulation model, 50,000 simulations were necessary for each value generated for POP on the dates evaluated, the results presented by the Finite Differences model are provided according to the grid represented in Figure 1. Thus, in one single application, POP values are generated for any time instance and underlying stock value dicretized. Therefore, Figure 2 presents the results graph for this model when applied to POP PETR70, having 09.02.2007 as start date. It is possible to notice that, regardless of the underlying stock value and the date, the POP price has a minimum limit. This amount is represented by the present amount of strike price for the put option at risk-free interest rate. On 09.12.2007, this limit is R $\$ 44.48$.

Before we begin the analysis of the results found, Figure 3 compares an investment made in POP PETR70 on 09.02.2007 with the investment made directly in its underlying stock. We may 
Table 1 - Convergence of the Model of Monte Carlo simulation.

\begin{tabular}{|c|c|c|}
\hline $\begin{array}{c}\text { Number of } \\
\text { simulations }\end{array}$ & $\begin{array}{c}\text { Estimated value } \\
\text { for POP } \\
\text { (R\$) }\end{array}$ & $\begin{array}{c}\text { Standard } \\
\text { deviation }\end{array}$ \\
\hline 1,000 & 46.138 & 0.1888 \\
5,000 & 46.161 & 0.0577 \\
10,000 & 46.128 & 0.0442 \\
20,000 & 46.137 & 0.0253 \\
30,000 & 46.138 & 0.0243 \\
40,000 & 46.130 & 0.0215 \\
50,000 & 46.140 & 0.0159 \\
\hline
\end{tabular}

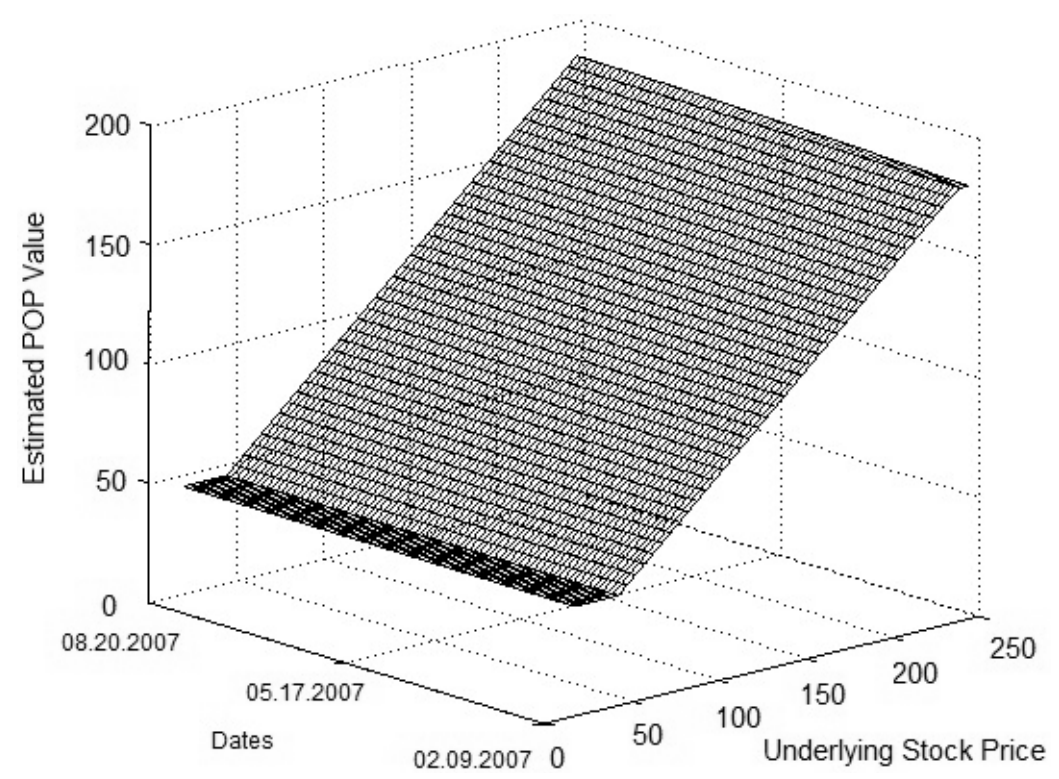

Figure 2 - Grid with results from POP evaluation (PETR70) from the Implicit Finite Differences Model.

notice, in the graph on the left, that the POP payoff at maturity date is limited at the bottom by $\mathrm{R} \$ 45$, which represents the strike price for the put option. On the other hand, for underlying stock values above $\mathrm{R} \$ 45$, POP payoff is inferior to the direct investment in the underlying stock, as the profit start to be shared with the holder of the call option. On 09.02.2007, the closing price for POP PETR70 and its underlying stock, Petrobras PN (PETR4), were R\$ 46.2 and R\$ 44.8, respectively. Therefore, the graph on the right in Figure 3 presents the comparison between the direct investment in the underlying stock and the investment in POP, for underlying stock values at maturity date between $\mathrm{R} \$ 0.00$ and $\mathrm{R} \$ 250$. The inferior limit for the stock price ( $\mathrm{R} \$ 45)$ locks POP profitability at a minimum threshold of $-2.6 \%$. Nevertheless, the return obtained in stock 
is always superior to that of POP's for stock value from $\mathrm{R} \$ 43.63$, but the difference rises as the stock value also rises.
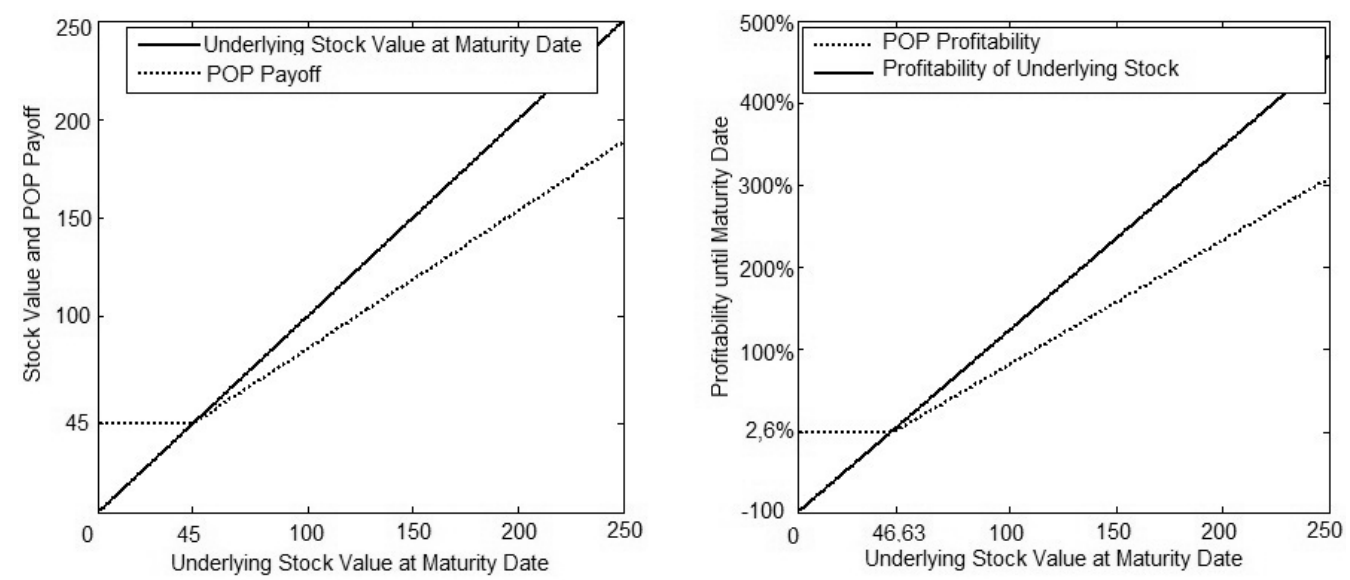

Figure 3 - Comparison between investment in POP (PETR70) and the investment in the underlying stock (PETR4) - in R\$.

Therefore, to acquire the stock through POP on 09.02.2007, that is, in conjunction with the protection offered by the put option and the possibility of profit sharing from the call option, the investor would be paying a difference of plus $\mathrm{R} \$ 1.4$ per stock $(\mathrm{R} \$ 46.2-\mathrm{R} \$ 44.8)$. Actually, this amount is what the investor would be paying implicitly to be the holder of put options, in relation to what he/she would be receiving as writer of call options. In this sense, POP value may also be estimated by the sum between the underlying stock value in the spot market and the premium of the put options, subtracting the premium from the call options. Although the two models developed in this article work jointly with the call and put options, the value of each option could be obtained individually by a simple change in the boundary conditions. Notwithstanding, for the purposes of comparing the results obtained in the two models, besides the actual closing values for the security, the premiums from the call and put options implicit in each POP will be evaluated from Black \& Scholes' formula (1973), so that the POP value will still be estimated by the equation (21).

$$
P O P=S_{V}+P_{O V} B \& S-(1-P P) \times P_{O C} B \& S
$$

where $S_{V}$ is the cash price of the underlying stock, $P_{O V} B \& S$ is the premium for the put option obtained by Black \& Scholes' formula, and $P_{O C} B \& S$ is the call option premium obtained from the same formula.

Tables 2, 3, 4 and 5 refer, respectively, to the evaluation of the results of models when they are applied to POPs analyses: PETR70, PETR80, VALE70 and VALE80. These tables display, in the first column, the dates when the models were tested, that is, February $9^{\text {th }}$ and February $23^{\text {rd }}, 2007$. The second column displays the closing prices for the respective referenced stock. The POP closing price is presented in the third column. The fourth and sixth columns display, respectively, 
the results found by the models of Implicit Finite Differences and Monte Carlo simulation. The fifth and seventh columns, in their turn, present the percentage differences between the results found by each model and POP closing price. The estimated POP value from equation (20) is presented in the eighth column, and the ninth column displays the percentage difference in relation to closing price of the security. Thus, as regards the implicit call and put options for POP PETR70, the values found by Black \& Scholes formula for 09.02.2007 are, respectively, R 3.14 and $R \$ 2.30$, generating, from equation (20) a POP value of $R \$ 46.16(R \$ 44.8+R \$ 3.14-0.3$ $\times \mathrm{R} \$ 2.3$ ), as shown in Table 2 .

Observing the data from Tables 2 to 5 we may notice that, generally speaking, the POPs analyzed were negotiated at prices above those found by the two models developed or by Black \& Scholes estimation (1973), even if the latter and the Monte Carlo simulation model have presented values which are closer to the security closing price. Still, the Finite Differences model presents the differential of, in one single application, generate the security values for any underlying stock price and time instance, as represented in grids from Figures 1 and 2. This characteristic enables the visualization of security price behavior along time.

Table 6 presents two measurements as for the adherence of the models to the security closing prices. The first one represents the sum of the square differences between the values found by the model and the security closing prices. Observing this measurement, we confirm the higher adherence observed by the Monte Carlo simulation model and by the estimation by Black \& Scholes. The second measurement represents the average modules of the differences. Thus, even if these securities have not yet reached the liquidity intended, we may notice that the estimated prices remained close to the security closing price. The maximum difference observed by the three models was in the evaluation of POP PETR70, being 3\% for the Finite Differences model, $1.29 \%$ for the Monte Carlo simulation model and $1.16 \%$ for the estimation by Black \& Scholes.

It is important to highlight that the analyses consider only one given time period, where the stock and derivatives values do not present substantial variations. The great similarity between the theoretical results and POP price in the market may be only a coincidence, due to market mood at that specific period, which by no means renders these important results void, as they show that the values obtained by Finite Differences and by MCS coincide.

In addition to the pricing itself, the models developed allow the sensitivity analyses for the security value against the changes of input parameters values, not only for those related to variables that require an estimation - as well as the risk-free interest rate and the volatility -, but also those that define their own security features, such as strike price for the options or the percentage of participation defined for each POP series. Therefore, it enables not only the comparison of POPs with different characteristics, but also a better visualization of the risks involved in the security, which may originate from a sudden change in the estimated input parameters or even a poor estimate thereof.

As examples of analyses that may be performed, Table 7 displays the results obtained from gains at $10 \%$ for the original values used for the risk-free interest rate, the volatility of the underlying 


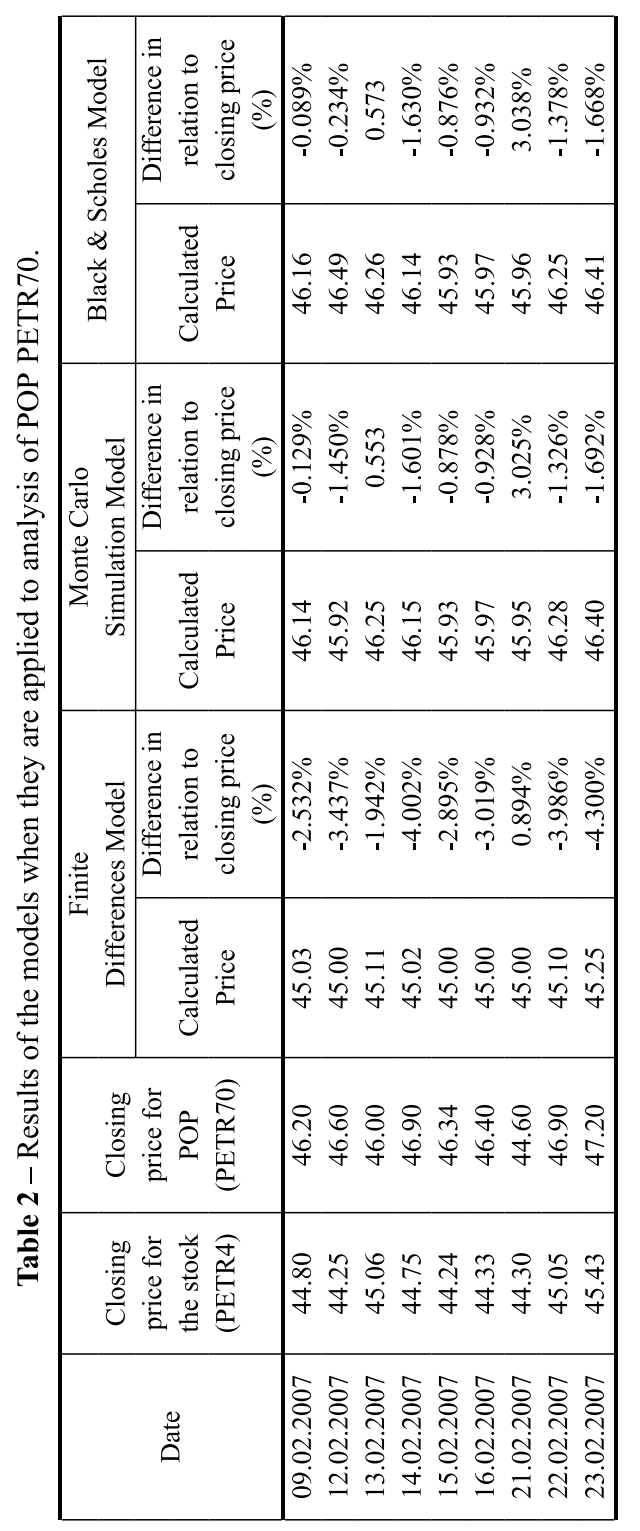

\begin{tabular}{|c|c|c|}
\hline \multirow{2}{*}{ 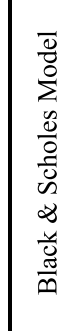 } & 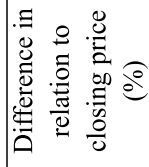 & 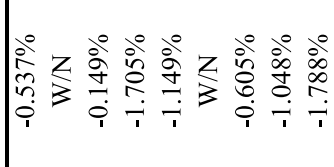 \\
\hline & 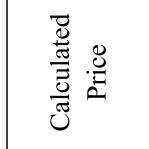 & 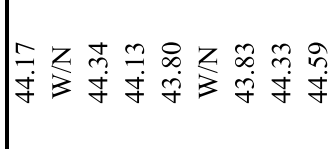 \\
\hline \multirow{2}{*}{ 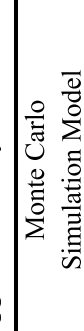 } & 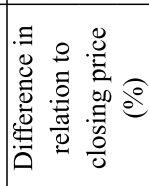 & 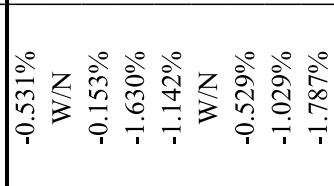 \\
\hline & 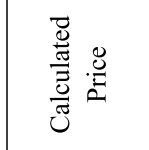 & 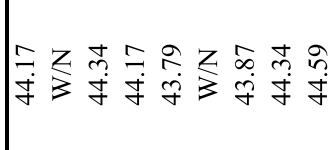 \\
\hline \multirow{2}{*}{ 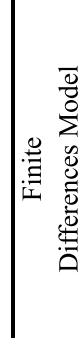 } & 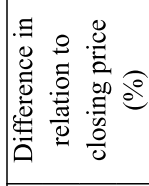 & 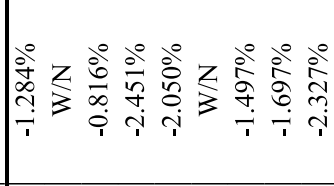 \\
\hline & 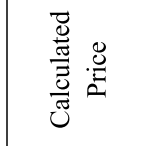 & 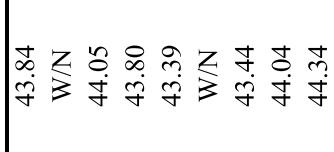 \\
\hline \multicolumn{2}{|c|}{ 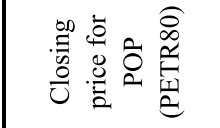 } & 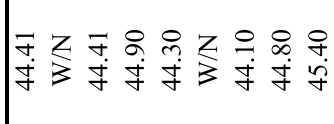 \\
\hline \multicolumn{2}{|c|}{ 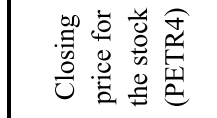 } & 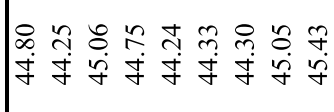 \\
\hline & $\stackrel{\mathscr{\pi}}{0}$ & 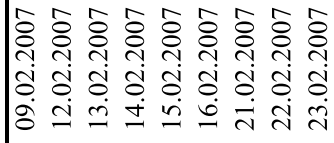 \\
\hline
\end{tabular}




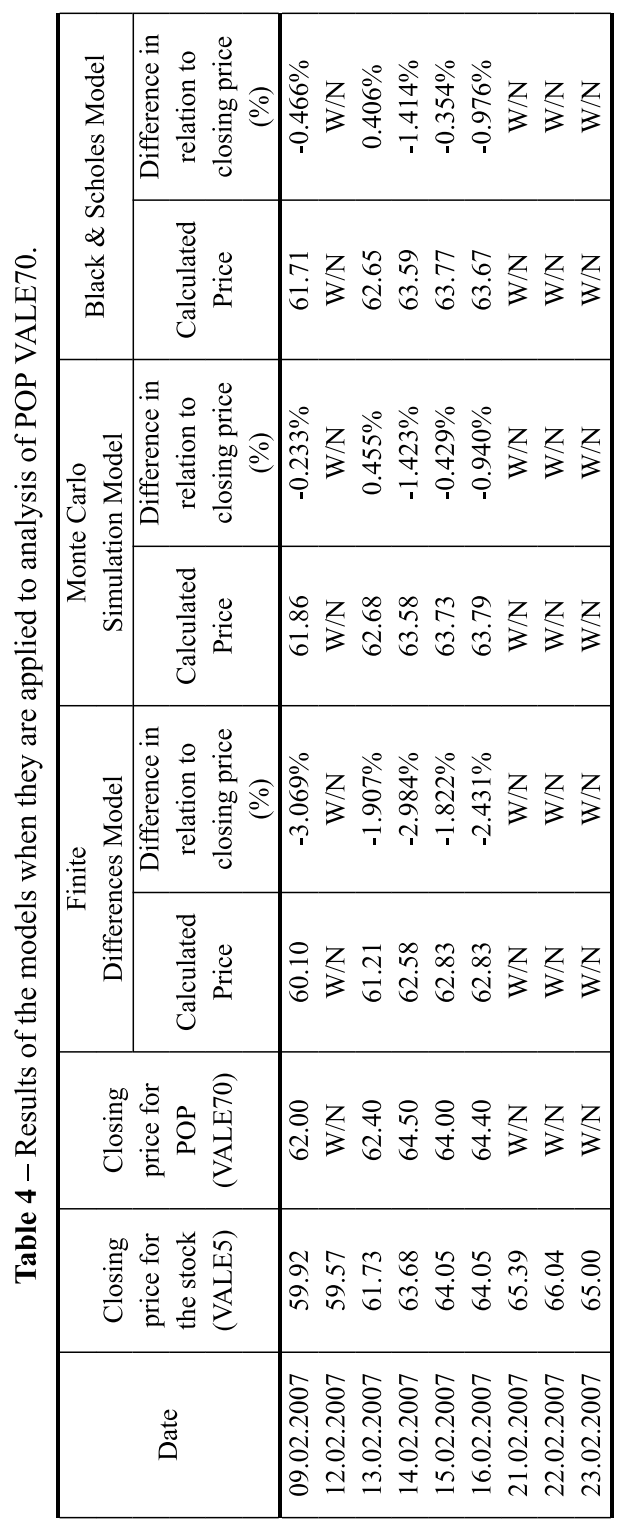

\begin{tabular}{|c|c|c|}
\hline \multirow{2}{*}{ 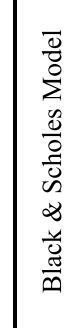 } & 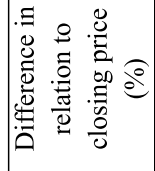 & 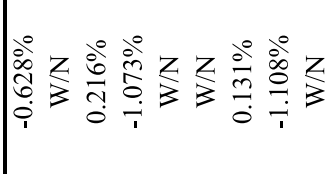 \\
\hline & 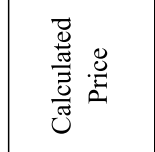 & 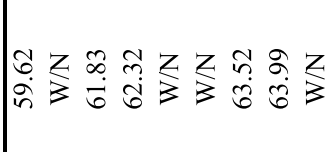 \\
\hline \multirow{2}{*}{ 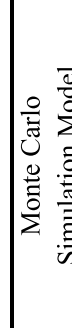 } & 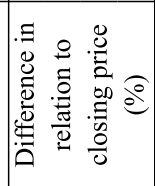 & 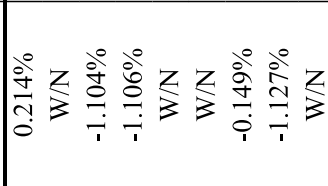 \\
\hline & 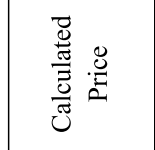 & 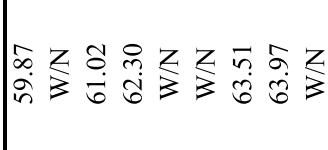 \\
\hline \multirow{2}{*}{ 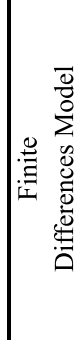 } & 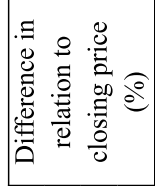 & 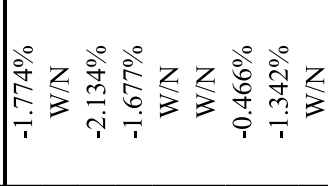 \\
\hline & 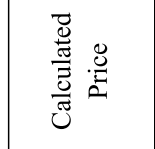 & 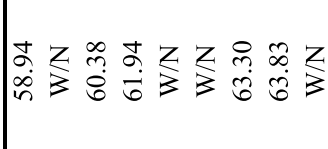 \\
\hline \multicolumn{2}{|c|}{ 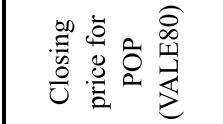 } & 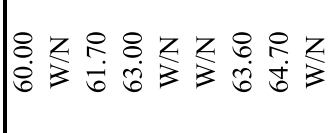 \\
\hline \multicolumn{2}{|c|}{ 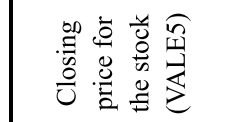 } & 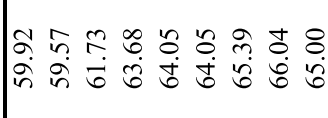 \\
\hline & 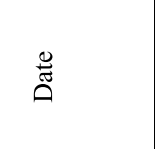 & 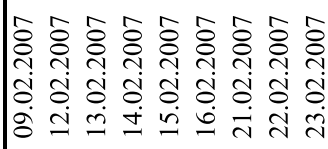 \\
\hline
\end{tabular}


Table 6 - Adherence of the models to closing price.

\begin{tabular}{|c|c|c|c|c|c|c|}
\hline \multirow{2}{*}{ POP } & \multicolumn{2}{|c|}{ Finite } & \multicolumn{2}{c|}{$\begin{array}{c}\text { Monte Carlo } \\
\text { Simulation Model }\end{array}$} & \multicolumn{2}{c|}{ Black \& Scholes Model } \\
\cline { 2 - 7 } & $\begin{array}{c}\text { Differences Model } \\
\text { Sum of } \\
\text { squared } \\
\text { differences }\end{array}$ & $\begin{array}{c}\text { Average of } \\
\text { modules of } \\
\text { differences }\end{array}$ & $\begin{array}{c}\text { Sum of } \\
\text { squared } \\
\text { differences }\end{array}$ & $\begin{array}{c}\text { Average of } \\
\text { modules of } \\
\text { differences }\end{array}$ & $\begin{array}{c}\text { Sum of } \\
\text { squared } \\
\text { differences }\end{array}$ & $\begin{array}{c}\text { Average of } \\
\text { modules of } \\
\text { differences }\end{array}$ \\
\hline PETR70 & 0.907 & $3.00 \%$ & 0.204 & $1.29 \%$ & 0.186 & $1.16 \%$ \\
PETR80 & 0.231 & $1.73 \%$ & 0.088 & $0.97 \%$ & 0.092 & $1.00 \%$ \\
VALE70 & 0.312 & $2.44 \%$ & 0.034 & $0.70 \%$ & 0.035 & $0.72 \%$ \\
VALE80 & 0.125 & $1.48 \%$ & 0.038 & $0.74 \%$ & 0.028 & $0.63 \%$ \\
\hline
\end{tabular}

Table 7 - Sensitivity Analysis.

\begin{tabular}{|c|c|c|c|c|c|c|c|}
\hline & \multirow{2}{*}{$\begin{array}{c}\text { Value of } \\
\text { variable after } \\
\text { gain of } 10 \%\end{array}$} & \multicolumn{2}{|c|}{$\begin{array}{c}\text { Finite } \\
\text { Differences Model }\end{array}$} & \multicolumn{2}{|c|}{$\begin{array}{c}\text { Monte Carlo } \\
\text { Simulation Model }\end{array}$} & \multicolumn{2}{|c|}{ Black \& Scholes Model } \\
\hline & & $\begin{array}{l}\text { Calculated } \\
\text { Price }\end{array}$ & $\begin{array}{l}\text { Difference \% } \\
\text { in relation to } \\
\text { base scenario }\end{array}$ & $\begin{array}{l}\text { Calculated } \\
\text { Price }\end{array}$ & $\begin{array}{l}\text { Difference \% } \\
\text { in relation to } \\
\text { base scenario }\end{array}$ & $\begin{array}{l}\text { Calculated } \\
\text { Price }\end{array}$ & $\begin{array}{l}\text { Difference \% } \\
\text { in relation to } \\
\text { base scenario }\end{array}$ \\
\hline $\begin{array}{l}\text { Risk-free interest } \\
\text { rate }(0.25 \text { days })\end{array}$ & $0.009884 \%$ & 5.03 & $-0.0004 \%$ & 6.11 & $-0.076 \%$ & 6.09 & $-0.141 \%$ \\
\hline $\begin{array}{l}\text { Volatility of underlying } \\
\text { stock ( } 0.25 \text { days })\end{array}$ & $1.041311 \%$ & 5.04 & $0.016 \%$ & 6.35 & $0.459 \%$ & 6.35 & $0.406 \%$ \\
\hline $\begin{array}{l}\text { Strike price for } \\
\text { the options }\end{array}$ & 49.5 & 9.50 & $9.921 \%$ & 9.33 & $6.922 \%$ & 9.34 & $6.888 \%$ \\
\hline $\begin{array}{l}\text { Percentage of } \\
\text { participation }\end{array}$ & $77 \%$ & 5.03 & $0.007 \%$ & 6.39 & $0.532 \%$ & 6.38 & $0.476 \%$ \\
\hline
\end{tabular}

stock, the strike price of the options and the percentage of participation, applied to POP PETR70 on February $9^{\text {th }}, 2007$.

We may notice that, considering the four changes studied, the greatest impact on the security price was generated by the gain of $10 \%$ in the strike price for the options. Also, regarding the parameters in the security, the percentage of participation generated, as expected, a raise in the security price, as it represents a smaller quantity of call options sold. However, the sensitivity to this parameter was low. The sensitivity regarding the volatility was substantial. Thus, in considering, in the model, a lower volatility that that expected in the market, the latter will tend do provide an overestimated value for POP against what, theoretically, the market would be willing to pay. On the other hand, in considering, in the modeling, a volatility which is higher than the practiced one, the model overestimated the security value. In relation to the risk-free interest rate, the reasoning is the opposite, as the security value reacts negatively to raises in this variable.

Finally, the POP PETR70 has also been taken as a basis to apply the methodology to estimate the probabilities to exercise the implicit call and put options in the product, being 09.02.2007 the date of analysis. Therefore, these probabilities were evaluated considering three different expectations of annual return for the underlying stock: $10 \%, 15 \%$ and $20 \%$. All of the other parameters for the estimation were identical to those used in the pricing model. As expected, the 
results presented in Table 8 indicate that the probability to exercise the put options is reduced as the expectation of return increases (ceteris paribus), while the probability to exercise the call options reacts on the opposite way, that is, it increases upon raises in the expectation of return from the investor (ceteris paribus). In practical terms, a raise in the probability to exercise a put option represent greater chances of the protection acquired to be effectively executed.

Table 8 - Evaluation of the Probabilities to Exercise the Options.

\begin{tabular}{|c|c|c|}
\hline $\begin{array}{c}\text { Expectation of annual } \\
\text { return from the investor }\end{array}$ & $\begin{array}{c}\text { Probability to exercise } \\
\text { the Put Options }\end{array}$ & $\begin{array}{c}\text { Probability to exercise } \\
\text { the Call Options }\end{array}$ \\
\hline $10 \%$ & $44.84 \%$ & $55.16 \%$ \\
$15 \%$ & $40.39 \%$ & $50.61 \%$ \\
$20 \%$ & $35.69 \%$ & $64.31 \%$ \\
$25 \%$ & $31.46 \%$ & $68.54 \%$ \\
\hline
\end{tabular}

\section{CONCLUSIONS}

The POP is a security whose evaluation involves quantitative and computer complexity, mainly as regards call and put options. Therefore, it is reasonable to assume that those characteristics of the security and the difficulties posed for its evaluation may explain the low demand POP still has in the market. Notwithstanding, this new product represents an interesting alternative, specially for the investor who is still not used to operate in the stock or options marked, as it allows access to these markets through one instrument only, without exposure to high levels of risk.

The establishment of a minimum sale price for the stock, represented by the strike price for put options, is POP's main attraction. In conjunction with the protection itself, another interesting and outstanding point in this security is that, when the investor acquires it, in addition to assuming a long position for the underlying stock and the put option, he/she assumes a short position for the call options, thus dropping the cost of protection from the possibility of sharing gains with the holder of a call option in case of rise of the underlying stock price. The flexibility of the percentage of the gains to be shared, obtained by the percentage of participation - currently defined by BM\&FBOVESPA in two levels, $70 \%$ and $80 \%-$, is also another interesting feature.

In this line, it is believed that the models developed in this work may represent an attractive tool for those interested in negotiating this security, thus enabling not only to find its fair price, but also to carry out sensitivity analyses for its value against changes in the input parameters for the models. At the same time, as regards specifically the model developed by the Monte Carlo simulation, it is possible to evaluate the probabilities to exercise the options, representing the chances of effectively using the protection offered by the put option or sharing the profits with the call option holder.

Although the difference between the results found by the models developed herein and the actual closing price for the product has remained slightly above the expected on certain dates, it is believed that these events are less and less usual to the extent that this investment alternative becomes more popular in the market and there is a raise in its negotiation volume. 
As for possible improvements and extensions of this work, other finite difference methods could be explored, such as the Explicit Finite Difference method, the Hopscotch method, the CrankNicholson method, or even the adaptations proposed by Brennan \& Schwartz (1978). In relation to the Monte Carlo simulation model, a suggestion for future improvement of the methodology developed herein would be the hybrid Quasi-Monte Carlo model, which appears as an alternative to the traditional Quasi-Monte Carlo model. Additionally, there is also the possibility of exploring the sampling and variance reduction techniques, such as the Antithetic Variables, since it is simple and proven reduction in the processing time. According to Araújo (2004), this is one of the most used techniques in finance, due to its simplicity. An interesting reference in the sense of exploring other variance reduction techniques would be Marins' work (2006), which analyses the several simulation techniques applied to options pricing, besides Frota's work (2003).

\section{REFERENCES}

[1] AraúJo RO. 2004. Avaliação de Opções Reais Através do Método dos Mínimos Quadrados de Monte Carlo. 137 p. Dissertação. Mestrado em Engenharia de Produção. Departamento de Engenharia Industrial, PUC-Rio.

[2] Barone-Adesi G \& Whaley RE. 1987. Efficient Analytic Approximation of American Option Values. Journal of Finance, 42: 301-320.

[3] BlaCK F. 1976. The Pricing of Commodity Contracts. Journal of Financial Economics, 3: 167-179.

[4] BLACK F. 1974. The Pricing of Complex Options and Corporate Liabilities. Graduate School of Business Administration, University of Chicago.

[5] Black F, Derman E \& Toy W. 1990. A One-Factor Model of Interest Rates and its Application to Treasury Bond Options. Financial Analysts Journal, p. 24-32.

[6] Black F \& SCholes M. 1973. The Pricing of options and Corporate Liabilities. Journal of Political Economy, 81: 637-659.

[7] Boyle PP. 1977. Options: A Monte Carlo Approach. Journal of Financial Economics, 4: 323-338.

[8] Brennan MJ \& Schwartz ES. 1978. Finite Difference Merhods and Jump Processes Arising in the Pricing of Contingent Claim: A Synthesis. Journal of Financial and Quantitative Analysis, 13: $162-474$.

[9] Cox J, Ross S \& Rubinstein. 1979. Option Pricing: A Simplified Approach. Journal of Financial Economics, 7: 229-264.

[10] Frota AEF. 2003. Avaliação de Opções Americanas Tradicionais e Complexas. Dissertação. 143 p. Mestrado em Engenharia de Produção, Departamento de Engenharia Industrial, PUC-Rio.

[11] Grant D, Vora G \& Weeks D. 1996. Simulation and Early-Exercise of Option Problem. Journal of Financial Engineering, 5(3): 211-227.

[12] Hull J. 2005. Options, Futures \& Other Derivatives. Prentice Hall, Sixth Edition.

[13] Iorio G, Samanez CP \& Raposo GS. 2006. Avaliação de títulos conversíveis com opções de compra e venda: uma aplicação dos métodos de simulação Grant, Vora e Weeks e Mínimos Quadrados de Monte Carlo. Revista de Economia e Administração, 5(4): outubro/dezembro. 
[14] Johnson HE. 1983. An Analytic Approximation to the American Put Price. Journal of Financial and Quantitative Analysis, 18: 141-148.

[15] LongstafF FA \& Schwartz ES. 2001. Valuing American Options By Simulation: A Simple Least-Square Approach. The Review of Financial Studies, 14(1): 113-147.

[16] Macmillan LW. 1986. Analytic Approximation for American Put Option. Advances in Futures and Options Research, 1: 119-139.

[17] Marins Jaqueline TM. 2006. Ensaios sobre a Aplicação de Técnicas de Redução de Variância em Simulação de Monte Carlo para Avaliação de Opções e de Risco de Crédito. 156 f. Tese. Doutorado em Administração de Empresas, Instituto Coppead de Administração, UFRJ.

[18] Merton RC. 1973a. Theory of Rational Option Pricing. Bell Journal of Economics and Management Service, 4: 141-183.

[19] Merton RC. 1973b. The Relationship between Put and Call Prices: Comment. Journal of Finance, 28: $183-184$.

[20] Samanez CP, Iorio G, Raposo GS \& Palmeira M. 2002. Avaliação de Títulos Conversíveis com Opções de Compra e Venda. Revista de Economia e Administração, 1(4): 57-71, outubro/dezembro.

[21] VASICEK OA. 1977. An Equilibrium Characterization of the Term Structure. Journal of Financial Economics, 5: 177-188. 